16 a 18 de outubro de 2019 - Campinas | Brasil

\title{
Placas Planas Cimentícias para uso na Construção a Seco.
}

\section{Larissa F. da Silva*, Natasha K. de Paula, Victor de P. e Silva, prof. Carlos Marmorato .}

\section{Resumo}

O presente teve como objetivo principal o desenvolvimento de placas planas à base de óxido de magnésio para uso na construção à seco, por exemplo, sistemas construtivos com Light Steel Frame (LSF) e Drywall.Como sabe-se, no Brasil a construção civil se caracteriza por processos predominantemente artesanais, especialmente devido a limitações tecnológicas e operacionais. Neste sentido, se faz necessário o desenvolvimento de novas técnicas e produtos que permitam ganhos em processos mais industrializados e padronizados, tal como apresentado nesta pesquisa.

\section{Palavras-chave:}

Placas Planas, Cimento Magnesiano, Construção a seco.

\section{Introdução}

$\mathrm{Na}$ construção a seco, por exemplo, em sistemas como o Light Steel Frame, o uso de placas cimentícias tem ganhando destaque devido à facilidade de seu emprego e rapidez de implantação. No que se refere ao cimento Portland, principal aglomerante usado na produção destes elementos, também pode-se enfatizar os altos índices de emissões de $\mathrm{CO}_{2}$ que estão relacionados à sua produção, bem como a escassez de matérias-primas, especialmente 0 calcário para os próximos seiscentos anos.

Objetivos: A alternativa apresentada foi o emprego de aglomerantes alternativos derivados de rochas magnesianas, por exemplo, conhecido como cimento Sorel, que possui em muitas aplicações propriedades similares ao cimento Portland, bem como possibilita o emprego de fibras naturais ou sintéticas para produção de compósitos de baixo custo. Dentro deste contexto, o presente projeto propôs o estudo destes elementos de forma comparativa às convencionais placas cimentícias de fibrocimentos.

\section{Resultados e Discussão}

$\mathrm{Na}$ figura a seguir são apresentadas as placas produzidas em laboratório

Figura 1: Placas Planas

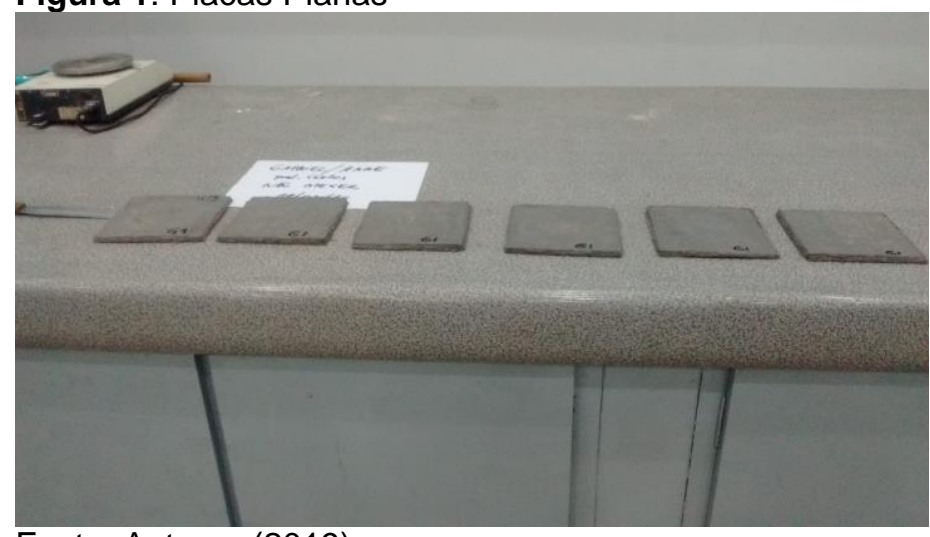

Fonte: Autores (2019)

$\mathrm{Na}$ tabela a seguir, são apresentadas as formulações estudadas:

Tabela 1. Formulações.

\begin{tabular}{|l|c|c|c|c|}
\hline Tipo & $\begin{array}{c}\mathrm{MgO/} \\
\text { Calcário } \\
(\%)\end{array}$ & $\begin{array}{c}\mathrm{MgCl}_{2} \\
(\%)\end{array}$ & $\begin{array}{c}\text { Fibra } \\
\text { PVA } \\
(\%)\end{array}$ & $\begin{array}{c}\text { Fibra } \\
\text { Celulose } \\
(\%)\end{array}$ \\
\hline Placa A & $\begin{array}{c}14,25 / \\
80,75\end{array}$ & $20 \%$ & 1,8 & 3,0 \\
\hline Placa B & $\begin{array}{c}23,75 / \\
71,25\end{array}$ & $20 \%$ & 1,8 & 3,0 \\
\hline Placa C & $\begin{array}{c}14,25 / \\
80,75\end{array}$ & $40 \%$ & 1,8 & 3,0 \\
\hline Placa D & $\begin{array}{c}23,75 / \\
71,25\end{array}$ & $40 \%$ & 1,8 & 3,0 \\
\hline
\end{tabular}

Abaixo são apresentados os resultados dos ensaios mecânicos, tração na flexão, obtidos por meio da NBR 15.948, média de 06 exemplares

Tabela 2. Resultados.

\begin{tabular}{|l|l|l|l|}
\hline Tipo & $\begin{array}{l}\text { Ensaio a } \\
\text { seco } \\
(\mathrm{MPa})\end{array}$ & $\begin{array}{l}\text { Ensaio } \\
\text { Saturado } \\
(\mathrm{MPa})\end{array}$ & $\begin{array}{l}\text { Ensaio } \\
\text { envelhecido } \\
(\mathrm{MPa})\end{array}$ \\
\hline Placa A & 3,60 & 2,55 & 3,50 \\
\hline Placa B & 5,90 & 3,90 & 7,40 \\
\hline Placa C & 4,35 & 2,90 & 3,95 \\
\hline Placa D & 7,75 & 4,45 & 5,35 \\
\hline
\end{tabular}

\section{Conclusões}

Após os ensaios, vimos que, os corpos-de-prova que continham uma quantidade maior de sal e óxido de magnésio, apresentarem resistência mecânica maior e as placas produzidas poderiam ser enquadradas dentro dos limites da NBR 15.948 - Placas Cimentícias, para uso na construção a seco.

\section{Agradecimentos}

À PRP da Unicamp, ao SAE, ao CNPq e ao Grupo de Pesquisa $\mathrm{GMC}^{3}$, prof. Carlos Marmorato.

GOMES, C.E.M; CAMARINI, G. NOCMAT 2013 - Magnesium Oxysulfate Fibercement, 14th International Conference on Non Conventional Construction Materials and Technologies - João Pessoa/BRAZIL, 2013. Key Engineering Materials Vol. 600 (2014) pp 308-318.

GOMES, C. E. M.; Alternative Binder for Fibercement Building Materials. Advanced Materials Research Vols. 753-755 (2013) pp 616-622. 2013

GOMES, C. E. M.. Magnesio Oxisulfato como Aglutinante para Productos de Fibrocimento. In: SAM-CONAMET 2013, 2013, Pto Iguazú. 13 Congreso Internacional en Ciencia y Tecnologia de Matalurgia y Materiales, 2013. 